\title{
Soy Isoflavones Reduce Toll-like Receptor-2 Levels in Acne Vulgaris
}

\section{Puguh Riyanto ${ }^{1 *}$ and Rosa Lelyana ${ }^{2}$}

${ }^{1}$ Department of Dermatology and Venereology, Faculty of Medicine, Diponegoro University, Kariadi Hospital, Semarang, Indonesia

${ }^{2}$ Faculty of Medicine, Diponegoro University, Semarang, Indonesia

\begin{abstract}
Background: Acne vulgaris (AV) is one of the most common skin inflammatory diseases. The results studies proved that soy isoflavones have anti-androgenic and anti-inflammatory. The objective of this study was to analyze the effect of soy isoflavone in AV lesions in women with AV.

Method: Randomized pre- and post-test control design, with 40 women, randomized into 2 groups: placebo and treatment. This study has done for 12 weeks. Soy isoflavones regarded as independent variable. AV lesions regarded as dependent variable and TLR-2 as intervening variable.

Results: The study found a reduction in total AV lesions after treatment, from $80.0 \pm 5.27$ to $78.8 \pm 27.46$ in the placebo group and from $83.8 \pm 37.82$ to $34.0 \pm 24.82$ in the treatment group, with a significant mean difference $(p<0.05)$. TLR-2 level has increased from $4505.5 \pm 3084.0 \mathrm{pg} / \mathrm{ml}$ to $6005.6 \pm 3376.66 \mathrm{pg} / \mathrm{ml}$ in the placebo group and decreased from $4574.1 \pm 2701.06 \mathrm{pg} / \mathrm{ml}$ to $1883.6 \pm 2479.04 \mathrm{pg} / \mathrm{ml}$ in the treatment group with a significant mean difference $(p<0.05)$. The relationship between delta total acne lesions and TLR2 do Spearman were significant ( $p: 0.008 ; r: 0.650)$.

Conclusion: The treatment of $160 \mathrm{mg} /$ day soy isoflavones for 12 weeks in women with suffered AV lesions has proved a significant reduction in total $\mathrm{AV}$ lesions cause of the reduction in TLR-2 levels.
\end{abstract}

Keywords: Acne vulgaris; Soy isoflavones; AV lesions; TLR-2

\section{Introduction}

Acne vulgaris (AV) is a chronic inflammatory skin disease of the pilosebaceous unit and one of the most common skin diseases. Acne vulgaris is a multifactorial process which has four main factors, such as excess sebum production, hypercornification of the pilosebaceous ducts, inflammation caused by the colonization of Propionibacterium acnes ( $P$. acnes), and microcomedone caused by hyperkeratosis in the infundibulum of the pilosebaceous duct, corneocyte cohesion, and sebum secretion [1-3].

Toll-like receptor-2 (TLR-2) is a membrane receptor, a part in the innate immune system. TLR-2 will bind the peptidoglycans in $P$. acnes cell wall and activate the inflammatory response through the nuclear factor kappa B (NF- $\kappa B$ ) pathway, whereas interleukin-8 (IL-8) is known as a central inflammatory mediator. One of the role of IL- 8 is a neutrophil chemotactic factor in the pathogenesis of AV [4-9].

Several factors that correlated with AV are age, psychological stress, nutritional status, genetic, race, nutrition, occupation, pregnancy, oxidative stress, chemical substances exposure, environmental pollutant, ultraviolet, and hyperandrogenism [1,10-14].

Isoflavones are flavonoids that have activity as antioxidant and inhibitor of inflammation [15-18]. Isoflavone has inhibited nuclear factor-kappa B (NFkB) pathway, mitogen-activating protein (MAP) kinase and several cellular signaling, so could decreased the expression of pro-inflammatory cytokines IL-1, IL-8, and tumor necrosis factor (TNF)- $\alpha$. Results studies found that isoflavone inhibited inflammatory response [19-23]. Another study used rat brain tissue has found that soy isoflavone was able to reduce TLR-2 levels [23].

\section{Methods}

The present study utilized a randomized pretest-posttest control group design. The treatment group was given $160 \mathrm{mg}$ /day soy isoflavones and the control group was given placebo. The duration of this study was 12 weeks. Forty subjects that were randomized into 2 groups. This study was monitored using schedule of assessment visit guidelines to manage the drop out. Women were treated at RSUP dr Kariadi Semarang. Study subjects were chosen using consecutive sampling method and treatments were given using double blind methode. Standard medication given were $0.025 \%$ tretinoin cream and SPF 15 sunscreen, whereas the soy isoflavones used in the current study was the soy isoflavone produced and standardized by the pharmaceutical industry Nu-Health, California, United States of America. Inclusion criteria were female AV patients for the last 3 months, not under any medication, and agree to sign the informed consent form. Exclusion criteria were allergy to soy isoflavone. The independent variable was $160 \mathrm{mg} /$ day soy isoflavone, and the dependent variable was the severity of AV according to Lehmann classification [5].

Two dermatologists assessed the severity of AV, and the variability was then calculated using interclass correlation coefficient and alpha coefficient. The intervening variables in the current study were TLR-2 serum levels in AV patients based on the result of ELISA. The controlled confounding factors were age, body mass index (BMI), and stress status based on Beck depression inventory (BDI) score [12]. Difference test was used to analyze the difference in total AV lesion and TLR-2 levels. Statistical significance level was defined at $\mathrm{p}<0.05$ with $95 \%$ confidence interval.

The Ethic Committee of the Faculty of Medicine Diponegoro

*Corresponding author: Puguh Riyanto, Department of Dermatology and Venereology, Faculty of Medicine, Diponegoro University, Indonesia, Tel: 0815764 5736; E-mail: Puguhungaran@gmail.com

Received: March 01, 2017; Accepted: March 15, 2017; Published: March 21 2017

Citation: Riyanto P, Lelyana R (2017) Soy Isoflavones Reduce Toll-like Receptor-2 Levels in Acne Vulgaris. J Nanomed Nanotechnol 8: 430 doi: 10.4172/2157 7439.1000430

Copyright: ( 2017 Riyanto $P$, et al. This is an open-access article distributed unde the terms of the Creative Commons Attribution License, which permits unrestricted use, distribution, and reproduction in any medium, provided the original author and source are credited. 
University/Dr. Kariadi General Hospital Semarang had approved the current study.

\section{Results}

Mean age for all subjects in the current study was $23.4 \pm 6.01$ years, ranging from 17 to 34 years old. Mean age was $23.7 \pm 5.98$ years in the control group, and $23.1 \pm 5.16$ years in the treatment group. Independent $t$ test showed no significant difference between the two groups ( $\mathrm{p}>0.05)$.

Mean BMI for all subjects in the current study was $21.2 \pm 2.30$, ranging from 13.3 to 25.4. Mean BMI was $20.9 \pm 3.62$ in the control group and $19.9 \pm 8.70$ in the treatment group. Mann Whitney test showed no significant difference between the two groups ( $p>0.05$ ).

On the whole, most AV patients in the current study showed no stress caused by AV, where 32 subjects (79.9\%) showed normal BDI score and 8 (20.1\%) showed mild BDI score. Chi square test showed no significant difference in BDI score between the two groups $(\mathrm{p}>0.05)$.

Mean total AV lesion before treatment was $80.0 \pm 5.27$ in the control group and $78.8 \pm 27.46$ in the treatment group. After treatment for 12 weeks, both groups showed lower mean total AV lesions, specifically $83.8 \pm 37.82$ in the control group and $34.0 \pm 24.82$ in the treatment group. The difference or delta $(\Delta)$ for total AV lesion in the group that was given $160-\mathrm{mg} /$ day soy isoflavones supplementation was $-49.8 \pm$ 13.0, higher than the mean difference delta for total AV lesion in the control group, $1.2 \pm 22.19$. Mann Whitney test showed a significant difference $(\mathrm{p}<0.05)$ (Table 1).

Mean TLR-2 levels before treatment was $4505.5 \pm 3084.0 \mathrm{pg} / \mathrm{ml}$ in the control group and $4574.1 \pm 2701.06 \mathrm{pg} / \mathrm{ml}$ in the treatment group. After treatment for 12 weeks, TLR-2 levels increased to 6005.6 $\pm 3376.66 \mathrm{pg} / \mathrm{ml}$ in the control group, with mean delta of $1500.1 \pm$ $3541.73 \mathrm{pg} / \mathrm{ml}$, whereas the treatment group showed reduction in TLR-2 levels to $1883.6 \pm 2479.04 \mathrm{pg} / \mathrm{ml}$, with mean delta of $-2690.5 \pm$ $3349.11 \mathrm{pg} / \mathrm{ml}$. Mann Whitney test showed a significant difference in delta TLR-2 levels between the two groups $(\mathrm{p}<0.05)$ (Table 2).

The relationship between delta total acne lesions and TLR2 do Spearman correlation significance (p: 0.008) and the relationship between the two has showed the strength ( $r: 0.650)$.

\section{Discussion}

Subjects in the current study were 17-34 years of age, almost equal to the AV study in China were 21 years old and an Italian were between 20-24 years of age. Results studies showed that acne vulgaris involves almost $80 \%$ adolescent and young adults were 11-30 years old. Androgen hormone levels in women started to increase during early puberty, peaked in adulthood, and then started to dwindle during menopause [13].

Mean Body Mass Index of AV patients in the current study were $21.2 \pm 2.30$ showed normal nutritional status. BMI classifications are underweight $=\mathrm{BMI}<18.50$, normal $=18.50-24.49$, overweight $\geq 25.00$, and obese $\geq 30.00$. Body Mass Index is one of the factors contributing to AV. BMI has correlated with the severity of $\mathrm{AV}$, where patients with higher BMI usually have more severe AV [2].

Stress status in the current study was assessed using the BDI score. Most study subjects showed no psychological stress, where $22 \%$ has mild stress and none has moderate or severe stress. Several studies have investigated the correlation between stress and depression with $\mathrm{AV}$, using the BDI score as stress evaluation parameter. Stress was correlated with AV because it may directly or indirectly increase the sebaceous glands activities by stimulating the pituitary [1]. Sebaceous glands function was also influenced by corticotrophin-releasing hormone $(\mathrm{CRH})$, which was regulated by the pituitary, thus may suffer some changes as a response to stress [1-3].

The current study found a significant decrease in total AV lesions after the administration of $160 \mathrm{mg}$ soy isoflavones for 12 weeks. Soy isoflavones may influenced the AV lesion because it has anti-androgenic property that may reduce DHT levels, which in return will restore the pilosebaceous ducts, reduce sebaceous gland secretions, repair the keratinization of the infundibulum of pilosebaceous ducts, corneocyte cohesion and prevent the formation of microcomedone, thus reducing the number of closed or open comedones, and reducing the number of AV lesion [1,2]. Soy isoflavone plays an anti-inflammatory role by obstructing the pro-inflammatory mediators in AV, which will reduce the number of papules, pustules, and nodules, and thus reducing the number of AV lesions [19].

The administration of $160 \mathrm{mg}$ soy isoflavones is comparable with consuming 55 grams of crude soybean, or 1280 grams of tempeh, or 2400 grams of tofu, or $800 \mathrm{ml}$ of soy milk. In the current study, soy isoflavone supplementation showed no dermatological side effects such as pruritus, urticaria, erythematous skin eruption, or maculopapular eruption, and no gastrointestinal side effects such as nausea or diarrhea, and no hormonal disturbances such as menometrorrhaghia. Humans had consumed isoflavone as part of their soy diet for years with no proven side effects [20].

Acne vulgaris is a dynamic process, wherein increased sebum

\begin{tabular}{|c|c|c|c|c|}
\hline \multirow{2}{*}{ Groups } & N & \multicolumn{2}{|c|}{ Mean \pm SD total AV lesion } & Post \\
\cline { 2 - 4 } & & Pre & $78.8 \pm 27.46$ & $-1.2 \pm 22.19$ \\
\hline Control & 20 & $80.0 \pm 5.27$ & $34.0 \pm 24.82$ & $-49.8 \pm 13.0$ \\
\hline Treatment & 20 & $83.8 \pm 37.82$ & \\
\hline
\end{tabular}

*Mann Whitney, $\mathrm{p}<0.05$ significant.

Table 1: Acne vulgaris lesion before and after treatment, and the delta value for control and $160 \mathrm{mg}$ isoflavone groups in female AV patients at Kariadi Hospital Semarang, August-October $2015(\mathrm{~N}=40)$.

\begin{tabular}{|c|c|c|c|c|}
\hline Groups & $\mathbf{n}$ & \multicolumn{2}{|c|}{ Mean \pm SDTLR-2 Level $(\mathbf{p g} / \mathbf{m l})$} & $\mathbf{P}$ \\
\cline { 3 - 5 } & & Pre & Post & \\
\hline Control & 20 & $4505.5 \pm 3084$ & $6005.6 \pm 3376.66$ & $97.4 \pm 320.72$ \\
\hline Treatment & 20 & $4574.1 \pm 2701.06$ & $1883.6 \pm 2479.04$ & $-2690.5 \pm 3349.11$ \\
\hline
\end{tabular}

*Mann Whitney, $\mathrm{p}<0.05$ significant.

Table 2: TLR-2levels before and after treatment, and the delta value for control and $160 \mathrm{mg}$ isoflavone groups in female AV patients at Kariadi Hospital Semarang, AugustOctober $2013(\mathrm{~N}=40)$. 
Citation: Riyanto P, Lelyana R (2017) Soy Isoflavones Reduce Toll-like Receptor-2 Levels in Acne Vulgaris. J Nanomed Nanotechnol 8: 430. doi: 10.4172/2157-7439.1000430

production, hypercornification of the pilosebaceous ducts, formation of comedowns caused by androgens and inflammation plays a part in the progression of AV lesion [1].

In this study, administration of soy isoflavone dose of $160 \mathrm{mg} /$ day for 3 months in patients with acne vulgaris impairment of TLR2 meaningful in comparing the control group. There are a strong relationship between delta total acne lesions and TLR2 do Spearman. Toll-like receptor-2 is a specific receptor for endotoxins, especially cell wall peptidoglycan, of gram-positive extracellular bacteria, including $P$. acnes. Number of receptors in the cellular surface is inconsistent, but either up-regulation or down-regulation may occur [4]. Toll-like receptor-2 has in important role in recognizing pathogens presented to the infectious agents, and in mediating the production of cytokine required to develop an effective immunity [5]. Inflammation caused by peptidoglycan from P. acnes cell wall in AV lesion may activate the TLR2 receptors in mononuclear and polymorphonuclear cells in the vicinity of the sebaceous follicle. The bond between TLR-2 and peptidoglycan will induce the production of pro-inflammatory cytokines such as IL1, IL-8, IL-12, and TNF- $\alpha$ [1-3]. Soy isoflavoneshas anti-inflammatory effect, thus may be considered for future AV treatment, especially as the substitute for isotretinoin (13-cis retinoic acid; 13-cis RA), a systemic retinoid effective for severe acne treatment and, currently, the only drug that can induce permanent long term AV remission $[1,2]$. Retinoid will impede the $\mathrm{T}$ cell $\mathrm{Th} 17$ inflammatory responses, increase T regulatory cell (Treg) production, and regulate the expression of tolllike receptors (TLRs). An in vitro study in normal human monocyte found that every all-trans retinoic acid (ATRA) end product may decrease TLR-2 expression, but this effect has not been studied in patient receiving systemic retinoid [6]. There is lack of similar study regarding the relationship between soy isoflavonesandTLR-2, but one previous study about the anti-inflammatory effect of soy isoflavonesin rat brain tissue model for Alzheimer's showed that isoflavone may decrease the levels of TLR-2 involved in the inflammatory process [7]. Toll-like receptor- 2 and cytokines has become the new target for AV treatment by modulating the immune response. Photodynamic treatment for AV using topical aminolevulinic acid may decrease the expression of TLR-2 [8]. An in vitro study found that nicotinamide orniacinamide may decrease the expression of TLR-2 and IL-8 in keratinocyte cell culture from AV patients $[7,8]$.

\section{Conclusion}

The administration of $160 \mathrm{mg} /$ day soy isoflavones for 12 weeks caused a significant reduction in total AV lesions because of the reduction in TLR-2 levels.

\section{References}

1. Zanglein AL, Graber AM, Thiboutot DM, Strauss JS (2012) Acne vulgaris and acneiform eruptions. McGraw-Hill, Dalam.

2. Collier CN, Harper JC, Cantrell WC, Wang W, Foster KW (2008) The prevalence of acne in adults 20 years and older. J Am Acad Dermatol 58: 56-59.

3. Layton AM (2010) Disorders on the sebaceous glands. Dalam.

4. Kim J (2005) Review of the Innate Immune Response in Acne vulgaris: Activation of Toll-Like Receptor 2 in Acne Triggers Inflammatory Cytokine Responses. Dermatology 211: 193-198.

5. Ozlu E, Karadag AS, Ozkanli S, Oguztuzun S, Kilic M, et al. (2016) Comparison of TLR-2, TLR-4, and antimicrobial peptide levels in different lesions of acne vulgaris. Cutan Ocul Toxicol 35: 300-309.

6. An HJ, Lee WR, Kim KH, Kim JY, Lee SJ, et al. (2014) Inhibitory effects of bee venom on Propionibacterium acnes-induced inflammatory skin disease in an animal model. Int J Mol Med 34: 1341-1348.
7. Dispenza MC, Wolpert EB, Gilliland KL, Dai JP, Cong Z, et al. (2012) Systemic isotretinoin therapy normalizes exaggerated TLR-2-mediated innate immune responses in acne patients. J Invest Dermatol 132: 2198-205.

8. Jeong E, Hong JW, Min JA, Lee DW, Sohn MY, et al. (2011) Topical ALAPhotodynamic Therapy for Acne Can Induce Apoptosis of Sebocytes and Down-regulate Their TLR-2 and TLR-4 Expression. Ann Dermatol 23: 23-32.

9. Younis S, Blumenberg M, Javed Q (2016) Resistin gene polymorphisms are associated with acne and serum lipid levels, providing a potential nexus between lipid metabolism and inflammation. Arch Dermatol Res 308: 229-237.

10. Leyden JJ (1995) New understandings of the pathogenesis of acne. J Am Acad Dermatol 32: S15-25.

11. Lehmann HP, Robinson KA, Andrews JS, Holloway V, Goodman SN (2002) Acne therapy: a methodologic review. J Am Acad Dermatol 47: 231-240.

12. Baumann L, Keri J (2009) Acne (Type 1 sensitive skin): Cosmetic dermatology principles and practice. 121-127.

13. International Data Base (2004) Statistics by country for acne. Dalam: US Census Bureau.

14. Tahir CM (2010) Pathogenesis of acne vulgaris: Simplified. J Pakistan Assoc Dermatol 20: 93-97.

15. Azimi H, Fallah-tafti M, Khakshur AA, Abdollahi M (2012) A review of phytotheraphy of acne vulgaris: perspective of new pharmacological treatments. Fitoterapia 1-5.

16. Rahman I, Biswas SK, Kirkhan PA (2006) Regulation of inflammation and redox signaling by dietary polyphenols. Biochemical Pharmacology 72: 1439-1452.

17. Handayani RL, Yuehua C, Medrano TA, Samedi VG, Baker HV, et al. (2006) Soy isoflavones after expression of genes associated with cancer progression, including interleukin-8, in androgen-independent C-3 human prostat cancer cells. J Nutrition: 136: 75-78.

18. Henkel V, Moeller HJ, Ring J, Warret (2002) Screening for depression in adult acne vulgaris patients: tools for dermatologist. J Cosm Dermatol 1: 202-207.

19. Mackinnon ES, Rao LG (2012) Soyabean as a special functional food formula for improving women's health. Functional Food of the East 280-291.

20. Barbara DA, McCauley (2011) Breast cancer, estrogen, soy genistein, and other dietary factors: Towards an understanding of their mechanistic interactions. Nutrition and Food Science 35-42.

21. Cappel M, Mauger D, Thiboutot D (2005) Correlation between serum levels of insulin-like growth factor I, dehydroepiandrosterone sulfate, and dihydrotestosterone and acne lesion counts in adult women. Arch Dermatology 141: 333-338.

22. Charles C, Yuskavage J, Carlson O, John M, Tagalicud AS, et al. (2009) Effects of high-dose isoflavones on methabolic and inflammatory marker in healthy postmenopausal women. Menopause 16: 395-400

23. Basaria S (2009) Effect of high-dose isoflavones on cognition, quality of life androgens, and lipoprotein in post-menopausal women. J Endocrinol Invest 32: $150-155$. 